SPECIAL ISSUE PAPER

\title{
Sustaining International Partnerships: The European Master of Science Programme in Occupational Therapy, a Case Study
}

\author{
Irene llott $^{1 *}$, Anders Kottorp ${ }^{2}$, Karen la Cour ${ }^{3}$, Fenna van $\mathrm{Nes}^{4}$, Hans Jonsson ${ }^{5}$ \& Gaynor Sadlo ${ }^{6}$ \\ ${ }^{1}$ Sheffield Teaching Hospitals NHS Foundation Trust, Sheffield, UK \\ ${ }^{2}$ Zurich University of Applied Sciences, Winterthur, Switzerland \\ ${ }^{3}$ University of Southern Denmark, Denmark \\ ${ }^{4}$ Hogeschool van Amsterdam, Amsterdam, The Netherlands \\ ${ }^{5}$ Karolinska Institutet, Stockholm, Sweden \\ ${ }^{6}$ University of Brighton, Eastbourne, UK
}

\begin{abstract}
International partnerships are a mechanism for supporting the academic development of occupational therapy and promoting cultural competence. This case study describes the factors that have helped to sustain a post-qualifying programme implemented by five higher education institutions in Denmark, the Netherlands, Sweden, Switzerland and the UK since 1999. Data collection methods were documentary analysis and the reflections of a purposive sample of six key informants. Cohort and outcome data, from 193 students from 31 countries who enrolled between 1999 and 2011, are reported. Each cohort comprises students from an average of eight countries to optimize inter-cultural dialogue. Four factors support sustainability. These are 1) supportive professional European networks; 2) timeliness and alignment with European higher education policy; 3) partnership structures and processes that emphasize joint decision making and accountability; and 4) the stimulus and satisfaction associated with internationalization. The main limitations are considering the OT-EuroMaster as an intrinsic case study and using opportunistic data collection that undermines the rigor and transferability of the findings. Future opportunities include doctoral networks, transnational research and sharing our curricula design with other Regions to spread the collaborative, capacity building endeavours more widely. Copyright $\odot 2013$ John Wiley \& Sons, Ltd.
\end{abstract}

Received 1 March 2013; Accepted 6 March 2013

Keywords

occupational therapy post graduate education; global educational planning; case study; sustainability

*Correspondence

Irene Ilott, Sheffield Teaching Hospitals NHS Foundation Trust, Sheffield, UK.

Email: Irene.llott@sheffield.ac.uk

Published online 5 April 2013 in Wiley Online Library (wileyonlinelibrary.com) DOI: 10.1002/oti.1349

\section{Introduction}

There are two important dimensions to the internationalization of higher education. These are "internationalization at home" that refers to activities to help students develop international understanding and inter-cultural skills and "internationalization abroad" encompassing education across borders with mobility of students and faculty (De Wit, 2010). Both forms are intended to enhance cultural competence and sensitivity. Cultural competence is the combination of knowledge, attitudes 
and skills for dealing with diversity and challenging inequalities (Kinėbanian and Stomph, 2009). These competencies are vital for occupational therapists as many communities now comprise people from diverse sociocultural backgrounds. For example, in Sweden, $25 \%$ of the population has one parent originating from another country (Momeni et al., 2008), and about 20\% of the population of Germany and the Netherlands has a migration background (Knipper et al., 2010). Immigrants and ethnic minority groups are known to be vulnerable to inequalities in health, with disparities in access to services and quality of care (Knipper et al., 2010). Some recent literature highlights the practical difficulties of "internationalization at home" or integrating cultural competence into medical (Seeleman et al., 2009), nursing (Momeni et al., 2008) and occupational therapy curricula (Humbert et al., 2011). Humbert and colleagues (2011) noted that more education and exposure to multiple cultures is recommended in occupational therapy education.

This case study focuses on "internationalization abroad" as a mechanism for supporting the academic development of the profession. The case is the European Master of Science programme in Occupational Therapy, known as the OT-EuroMaster. This is a rare collaboration that delivers a post-qualifying programme in five European countries. Almost 20 years ago, a partnership between institutions in Denmark, the Netherlands, England and Sweden was formed to advance the academic status of the profession by creating an advanced master of science degree programme and to enable qualified occupational therapists to undertake higher level study. In the 1990s, the Diploma was the predominant entry level qualification throughout Europe. There were few opportunities to study bachelor, master and doctoral degrees in occupational therapy. In 1999, a survey of 274 schools in 19 European countries showed that most occupational therapy programmes were small, with an average of 30 students qualifying each year (ENOTHE, 2000). Occupational therapy education was located in Universities in only seven countries at that time. Enhancing the academic level of the profession was necessary to counter this situation and to respond to the increasing demands for evidence-based practice. The need to collaborate, to create a transnational partnership with the critical mass of academic staff and to be able to offer an advanced, scientific master programme for practicing therapists was one way of tackling the challenge.
Student mobility, in general, is relatively common in Europe. European higher education policies, especially the ERASMUS MUNDUS scheme (see http://ec.europa. eu/education/external-relation-programmes/ mundus_en.htm), promote the exchange of staff and students, recognizing the academic and personal development benefits that arise from international experience. Nonetheless, most international education programmes are delivered via distance learning or e-learning to students in various countries (Roberts et al., 2003), and students may travel to just one other country. In contrast, the course design team of the OT-EuroMaster made student mobility a primary feature of the curriculum design to highlight the criticality of inter-cultural dialogue for cultural competence. As far as we are aware, the OT-EuroMaster is the only programme where student and faculty mobility is so integral and intentionally reflects the essence of "internationalization abroad". Our curriculum requires students to study in five countries.

The lack of comparative international occupational therapy programmes became apparent to the course team in 2010, when the OT-EuroMaster was invited to participate in an evaluation of internationalism as a distinctive quality feature in higher education. The project was run by the NVAO, the independent accreditation organization set up by the Dutch and Flemish governments to judge the quality of higher education institutions and programmes (NVAO, 2010a). The opportunity to participate in the pilot, one of only 21 programmes in the Netherlands and Flanders to do so, made us appreciate that the OT-EuroMaster is in itself an intrinsic case study, having maintained complex, close international collaborations for many years. The aim of this case study is to identify the factors in the establishment, delivery and outcomes of the OT-EuroMaster that have contributed to its sustainability since 1999.

\section{Method}

The research design is an intrinsic case study using Appreciative Enquiry. In an intrinsic case study, the focal point is the particular situation and its complexities (Stake, 1995). The case is the OT-EuroMaster. Appreciative Enquiry is a "strengths-based" approach that explores the positives, the success factors or the "best of stories" regarding the phenomena of interest (Clarke and Reed, 2010). 
Data were collected from two sources: documents and a purposive sample of key informants. The three main documents were 1) an academic accreditation report (NVAO, 2009); 2) a report about internationalism as a distinctive quality feature (NVAO, 2010b); and 3) an independent survey of alumni and employers conducted by the SCO-Kohstamm Institut in 2009. The official, accreditation documents, comprising 75 pages, were chosen because they are in the public domain. The third document was the report of the 2009 survey of alumni and employers. The email survey was completed by 49 alumni who graduated between 2005 and 2008. The response rate was 65\% $(N=32)$ for graduates and 39\% $(N=19)$ of their employers. Finally, internal reports compiled by faculty and quality assurance staff, including cohort and thesis data and the policies that guide the partnership, provided supplementary data.

The inclusion criteria for the key informants were a representative from each partner institution with a longstanding, intimate knowledge of the OT-EuroMaster. The six authors are the key informants. Each offers a different understanding, as follows: two are founder members who instigated the programme; two have been faculty since 2003; one graduated from the programme in 2004; and one has been involved as an external advisor since 1999. The informants were asked to reflect on their experience about the factors that supported the sustainability of the OT-EuroMaster, individually and then at a face-to-face meeting in April 2012.

The documentary analysis was carried out by one author. The analysis started with immersion in the three main documents. This involved reading and re-reading, and then inductive coding by the external advisor to identify success factors that appeared to support the establishment and maintenance of the OT-EuroMaster. Next, the key informants reviewed the preliminary findings at a staff meeting. All were familiar with the documents through their contribution to the accreditations in 2009 and 2010. They also contemplated their everyday experience of working as a team member of the OT-EuroMaster. The discussion continued using email correspondence until consensus was reached about the factors that have sustained the programme.

\section{Results}

Four factors were identified as pivotal for sustaining the OT-EuroMaster from inception to the present. Firstly, being embedded in, and supported by the principal professional and educational networks in Europe. Next, is timeliness, particularly the goodness of fit with European higher education policy that enables "internationalization abroad". Thirdly, the programme is predicated on an equal partnership between the higher education institutions. Partnership working is evident in the shared values and vision, the programme design and management arrangements. Finally, the stimulus and satisfaction derived from an international programme. Although each factor is described separately, they are inter-dependent.

\section{Supportive professional networks}

Two international networks were instrumental at the start through their drive to enhance the academic standing of the profession across Europe. The first was the Council of Occupational Therapists for the European Countries (COTEC), established in 1986 with the purpose of coordinating the views of the National Associations of Occupational Therapy. Previously, each country's Association worked in a relatively isolated way, and practitioners knew little of occupational therapy in neighbouring countries. COTEC now represents 29 countries and more than 120,000 occupational therapists. The European Network for Occupational Therapists in Higher Education (ENOTHE), founded in 1995 with financial support from the European Union, was the second network. Through ENOTHE meetings, the diversity of occupational therapy education in the European Union became apparent, especially the lack of occupational therapy education within the former communist countries. Both networks were committed to expanding opportunities for post-qualifying study, particularly for teachers, as a way of raising the entry level qualification from diploma to bachelor level. Now, bachelor degrees are the main route to qualification to practice occupational therapy, with two European countries (Ireland and the UK) offering master level entry (COTEC, 2011). In the 1990s, only three countries, the UK, Sweden and Finland offered advanced master degrees in occupational therapy (Kinébanian et al., 2007). Post-qualifying, professional or scientific master programmes are now available in 11 European countries (COTEC, 2011).

Both networks continue to support the OT-EuroMaster, particularly through their participation in the accreditation events. This was acknowledged in the 2009 accreditation 
report that noted that the OT-EuroMaster "being eo ipso an international cooperative, has designed the aims and objectives of the curriculum in strong cooperation with other leading European educational institutes (via ENOTHE) and professional bodies (via COTEC). The active involvement of both international higher education and the professional field is really a strong point, since this makes the aims and objectives internationally relevant" (NVAO, 2009, p. 14).

\section{Timeliness - alignment with European higher education policy}

International cooperation is a fundamental principle of the European Union, particularly "internationalization abroad" that promotes education across borders. In 1999, 29 European countries signed the Bologna Declaration, accepting the importance of "educational co-operation in the development and strengthening of stable, peaceful and democratic societies" (Bologna Declaration, 1999, p. 1). Now, the Bologna Process facilitates the exchange of staff and students within the 47 countries of the European Higher Education Area; see http://www.ond.vlaanderen.be/hogeronderwijs/bologna/. The Bologna Process encourages the mutual recognition of qualifications and achievements between countries; the transfer of knowledge, faculty, students and research across national borders; and international orientation and discourse through engaging with people from different cultures. The OT-EuroMaster documents revealed that these principles, supported by the vision of the leaders of ENOTHE, were being enacted through the rationale underpinning the programme at the beginning. This coincided with the development of the Bologna Declaration.

\section{Partnership working}

This factor encompasses a shared vision, collaborative processes and structures for the management and delivery of the programme. Partnership working is described in detail to show how these principles were put into practice and because of the potential for transferability.

\section{A shared vision}

In the mid-1990s, a cooperative venture, with the aim of enhancing the academic status of occupational therapy in Europe, was formed between occupational therapy education providers in four countries. The founding partners were the Hogeschool van Amsterdam, University of Applied Sciences (The Netherlands), the University College Sjælland (Denmark), the University of Brighton (United Kingdom) and the Karolinska Institutet (Sweden). The planning phase lasted 5 years (1994 to 1999). The early days were described as challenging because faculty needed to negotiate to "ensure that the consortium was operating within the laws, rules and regulations of all the countries" (Kinébanian et al., 2007, p. 174) and to overcome these institutional obstacles. In 2008, the Zurich University of Applied Sciences (Switzerland) became the fifth partner.

This shared vision was vital and continues to underpin the programme. The aim is "to develop the quality of occupational therapy by supporting the academic development of the discipline of occupational therapy in Europe and beyond" (Board Policy 2008-2012). Every 4 years, this Policy is renewed through a consensual process where all partners participate and agree the future direction for the programme.

\section{Partnership structure: form and membership}

Partnership is evident at strategic and operational levels. At an organizational level, there is a Board that consists of a senior representative from each institution, student observers and an independent chair. At an operational level, there is a Programme Management Team, comprising the Educational Director, the Scientific Director and the Module Coordinators. This Team shares accountability for programme delivery, the quality of the student experience and co-ordination between the five institutions.

The partnership is formalized in a contractual agreement and the governance arrangements. The Memorandum of Co-operation states that "the cooperating institutions recognize that the quality of the learning experience for the students and output standards of the programme can only be assured by the institutions ... working together in a spirit of partnership and mutual respect" (Memorandum of Co-operation 2009, statement 7). Each year, the Management Team prepares an annual report that reviews the international cooperation and the results. This report is discussed with staff and student representatives, ratified by the Board and shared with partner institutions. 


\section{Partnership processes: participation and interaction}

Accountability is enacted through the clear roles and responsibilities of partners at all levels. For example, in 2004, the Hogeschool van Amsterdam (HvA) received the degree awarding power, and a year later, legal status was achieved when the Dutch Ministry of Education and Science approved the programme under the Law on Higher Education, with the HvA as an "appointed" institution. This means that the programme does not receive a financial subsidy from the Dutch government and that the European Master is self-funding from students' tuition fees. As such, each partner shares the costs and any losses.

Each institution is responsible for providing the necessary resources for staff and students. The Memorandum refers to access for students to all facilities, staff and services that are available for general use, including the library and information technology, and funding the necessary (inter-) institutional staff development by each participating institution in order to support the programme.

Faculty teach, co-supervise, co-examine, meet and engage in developmental activities in each country and across countries. The supervision and examination of the master thesis is organized so that staff from different institutes work together, as a capacity building mechanism. Another strategy stated in the Board Policy is "to strengthen staff development" (2008-2012) by increasing the number of faculty with doctorates. When the programme started in 1999, there were four; in 2012, there were 15; and four others are undertaking doctoral studies. All research projects are supervised and examined by faculty with a $\mathrm{PhD}$. Two faculty members are full professors having recently been awarded chairs on the basis of their academic achievements.

The strong formal and informal relations were noted in the 2009 accreditation report. "In a consortium framework - in particular in an international consortium - with many lecturers having a small appointment, fragmentation of focus and approaches lie in wait. Therefore managing and guiding the staff deserve special attention to secure the consistency within the entire master course. The audit panel observed that the executive programme management team succeed in safeguarding the required consistency in the OT programme. Not only through formal tools (contracts, module designs and the like) but also and in particular through effective communication and through the quarterly meetings. In spite of their varying locations the cohesiveness of the staff is remarkably strong" (November 2009 p30).

\section{Programme design and delivery}

Management of each module is the responsibility of the Module Coordinator and the teaching team in each country. The students learn and experience the culture of five European countries, with each cohort spending 2 weeks in each country per semester. In the sixth and final module, students undertake an individual small scale study in their own country or join an existing research group or collaborate in transnational studies. In the international accreditation, the "educational concept and the carousel principle in particular offer students a unique chance to learn in an international and culturally diverse environment" was judged as excellent (NVAO, 2010b, p. 8).

\section{Internationalization as stimulus and source of satisfaction}

Internationalization "at home and abroad" was designed into the programme to maximize the opportunities for inter-cultural learning. This was perceived as an outstanding factor, providing motivation and stimulus for students, alumni and faculty.

\section{International cohorts}

A total of 193 students were recruited from 31 countries between 1999 and 2011. Most $(n=167,86.5 \%)$ came from Europe, then Asia $(n=12,6 \%)$, Africa $(n=9,5 \%)$ and the Americas $(n=5,2.5 \%)$. In each cohort, there are students from an average eight countries, with a range of 6 to 11 countries. Ensuring such diversity is an intentional part of the admissions process, which aims to enhance opportunities for cultural exchange. Students represent 27 nationalities. One in five lives in another country. For example, there have been European students who live and work in Japan, Tunisia and Tibet. Their experience of migration adds another dimension to internationalism.

\section{International curriculum}

The interactive methods of learning and teaching are designed to promote inter-cultural comparisons and participation, particularly through problem-based 
learning and the action learning sets. The starting point of the problem-based tutorials is an elaboration and evaluation of each student's workplace circumstances and cultural influences. Students learn from each other through the constant, critical comparison of national health and social welfare policies, health care systems and occupational therapy. In this way, the academic discourse and professional dialogue challenges personal pre-understandings through exposure to different perspectives. Box 1 contains an example, to show how internationalism is embedded in the curriculum.

These academic experiences are complemented by experiential learning. Cultural understanding is deepened by sharing accommodation and socializing together, through cooking typical national meals for each other when students' live together in a shared house. In these formal and informal ways, the visible and invisible aspects of culture are explored through daily occupation.

\section{Outputs: international studies and perspectives}

Since 1999, there have been 13 cohorts with 193 students. The OT-EuroMaster did not run in 2009 and 2012. The 160th student graduated in January 2013. Twenty-two have withdrawn for academic or personal reasons, giving an attrition rate of $11 \%$. Eleven students are continuing, having been delayed because of illness, motherhood or for other reasons.

International perspectives are integral to the master thesis. Over a quarter of the thesis titles (45/160) include a country in the title. Table 1 contains some examples of the populations studied, the inter-cultural and cross-national studies.

The final thesis is presented as a paper for a scientific journal and reported at a public conference attended by family, colleagues, local occupational therapists, students and external examiners so that the findings from national studies are shared with an international audience. Between 2002 and February 2013, a total of 42 papers were published in peer reviewed journals. Most (35/42) were published in occupational therapy journals, including the Scandinavian Journal (17/42), the American Journal (4/42) and the Journal of Occupational Science (6/42). Seven were published in inter-disciplinary journals, for example Work.

In 2009, a survey of alumni and employers was conducted by an independent organization, the SCOKohstamm Instituut. The respondents worked in 13 countries in Europe, Africa and Asia. In response to an open question about the most outstanding experience, two thirds of the comments made by alumni (21/30) related to internationalism, culture and diversity. Table 2 contains typical quotations. They show the personal and professional learning gained from the exchange with peers practicing in different countries.

Graduates continue to be international, adding to the research capacity and body of knowledge of the profession. Twenty graduates have embarked on doctoral studies in Canada, Denmark, Germany, the Netherlands, Sweden and England. In 2012, the sixth alumni gained their $\mathrm{PhD}$. A group of alumni started an international network: the European Cooperation

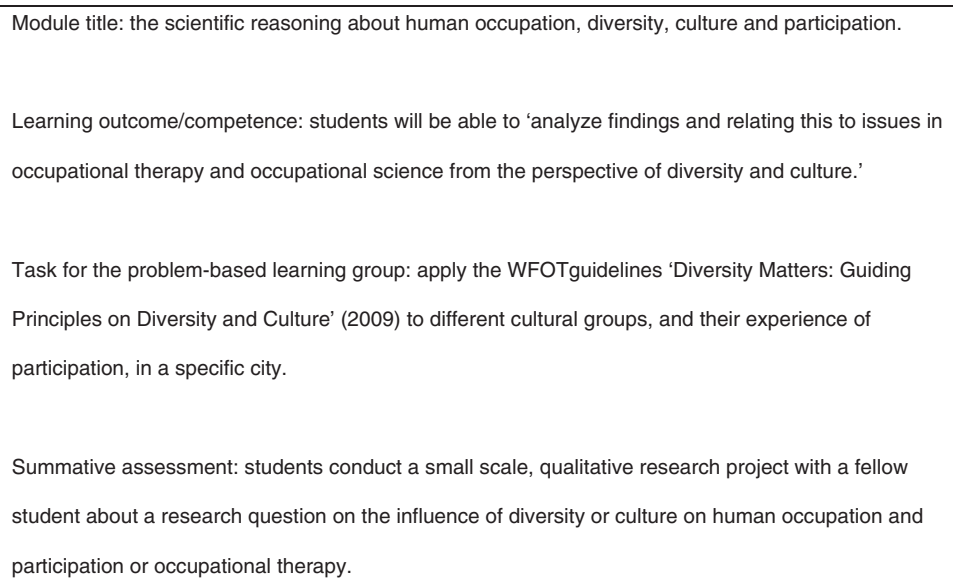

Box 1. Example of how internationalism is embedded in the OT-EuroMaster curriculum 
Table I. Examples of the international topics studied for the OT EuroMaster theses

\begin{tabular}{ll}
\hline International research themes & \multicolumn{1}{c}{ Research topics } \\
\hline People studied & Children with special needs in Tunisia \\
Elderly in adult care in South Korea & Persons with HIV in Namibia \\
& Displaced persons in Georgia \\
& Survivors of the tsunami in Thailand \\
& Children with disabilities in Tibet \\
& Persons with paraplegia in Tanzania \\
& Turkish women living in Germany \\
Children with disabilities in migrant families in the Netherlands & Albanians working in Switzerland \\
& Women's experience from a refugee camp in Austria \\
& Elderly Chilean immigrants living in Sweden \\
& Validity of an assessment measure in Germany and the Netherlands \\
& Participation experiences in school of children with disabilities in Portugal and Switzerland \\
& Participation of people with multiple sclerosis in Switzerland and Austria
\end{tabular}

in Occupational Therapy Research and Occupational Science. The graduates are contributing to the knowledge base through presentations; for example, at the 2010 World Congress in Chile, 10 alumni reported their master theses and 10 presented later work.

\section{Discussion}

This case study explored the factors that have sustained a novel educational partnership, offering "internationalization abroad" through the mobility of occupational therapy faculty and students for over a decade. The partnership between higher education institutions in Denmark, the Netherlands, England and Sweden was established for a specific purpose: to advance the academic status of the profession by creating an advanced master of science. The transnational partnership has thrived attracting 193 students from 31 countries between 1999 and 2011. Since 2002, 160 have graduated and six have completed $\mathrm{PhDs}$. There have been 42 publications in scientific journals. In 1999, when the programme started, only four faculty had $\mathrm{PhDs}$ and now there are 15. Two are full professors having been awarded chairs for their academic achievements.

A number of factors have supported the sustainability of the programme. These include the shared vision about academic development; the support of the two main European networks, COTEC and ENOTHE; and a good fit with European policy that promotes the international exchange of faculty and students. The delivery and management of the programme is based on an equal relationship and accountability. This is manifest in the structure and processes, the method of decision making and working together that maintain the programme. Internationalism is integral to all aspects of the programme. In each cohort, there are students from an average eight countries. This presents many opportunities for sharing inter-cultural perspectives and learning

Table II. Alumni feedback from the 2009 survey about the most outstanding aspect of the OT-EuroMaster

Sharing all these learning programmes with wonderful people from Europe and Africa.

Meeting occupational therapists from very different countries and finding out that we really have the same profession.

Building a network throughout Europe, getting to know people from various countries, with different expertise; staying at several countries for a couple of weeks and getting some insights into five higher eduation institutions.

Gaining knowledge and a first hand experience of doing research - especially transnational research.

Knowing how occupation is understood in European countries.

I was impressed by the variety of occupational therapy settings in Europe such as community services, public services, psychiatric hospitals and adult daycare because Korean occupational therapists work mostly in rehabilitation hospitals for people with physical disabilities.

The personal contact with OTs from Europe with the development of some deep friendships.

The cultural diversity of the cohort. 
about occupational therapy throughout the world. This is very satisfying for faculty and students, which is vital for sustainability.

\section{Methodological considerations}

A case study design, drawing on data from documentary analysis and the reflections of key informants, has both strengths and limitations. As far as we are aware, the OT-EuroMaster is a unique partnership between occupational therapy education providers in five countries. It was a natural, intrinsic case study. However, this limits the transferability of the findings about sustainability. One factor, the alignment between the programme and European Higher Education policy that promotes "internationalization abroad", is unlikely to be so prominent in other regions of the world. Data about sustainability were collected opportunistically, drawing on existing, easily available documents. The documentary analysis was carried out by one author, without recourse to any specific tools or frameworks, which limits rigor. The preliminary findings were discussed at a face-to-face meeting and in email exchanges, until agreement was reached about the four factors that supported sustainability. Two documents were from external validations conducted by senior academics from Europe and North America. The survey of alumni and their employers was carried out by an independent organization. These outsider perspectives complement the in-depth, insider knowledge of the key informants about the past, present and future challenges to sustainability. It is also important to acknowledge that Appreciative Enquiry is an approach that encourages positive perceptions by seeking success stories. However, these insider views are offset the judgement of external, academic peers in the accreditation reports, which strengthen the trustworthiness of the analysis.

\section{Lessons learned, challenges and opportunities}

Although the OT-EuroMaster operates in a specific geographical and policy context, the case study offers some pointers for creating similar partnerships in other parts of the world, particularly where resources are scarce. For example, seven Regional Groups are recognized by the World Federation of Occupational Therapists; see http://www.wfot.org/groups/regionalgroups.aspx including COTEC, the Occupational Therapy Africa Regional Group, the Arabic Occupational Therapists Regional
Group and the Asia Pacific Occupational Therapists Regional Group. These Groups provide a natural vehicle for collaboration to support academic development in a locality.

However, effective collaborations take time, commitment and appropriate structures and processes. The structure requires consensual decision making and shared accountability. The processes emphasize participation and personal interaction between students and staff to maintain relationships and the trust necessary to be co-supervisors and co-examiners. The partnership has set up special arrangements to support academic capacity building. For example, the new module in Switzerland is co-led by faculty from a well-established research university to support occupational therapy at an applied university to develop their academic standing.

English is the language of the programme. This has advantages and disadvantages. Although English is the dominant language in science and occupational therapy, this prevents linguistic pluralism and participation. However, occupational therapists interested in internationalization and research active faculty are competent and confident in both written and spoken English. A spin-off benefit is that the programme provides a supportive environment for academic discourse in English, as well as familiarity with the literature to inform evidence-based practice.

A challenge for international students is the crosscultural adaption to the norms of student-centred and small group learning. Problem-based learning and the action learning sets require students to be active not only in their own learning process but also towards their fellow students. This can be difficult for those used to didactic teaching methods and where competition between students is encouraged. Students can experience confusion about expectations, especially with giving and justifying their opinion. Initially, individuals and groups can have difficulties in functioning as a learning group when members of the group have very different expectations and educational experience. This is why in the first module, pedagogical approaches are introduced and students investigate learning as an occupation.

The ecological and financial implications of "internationalization abroad" are challenging. International travel draws attention to the carbon footprint. Air travel is vulnerable to natural disasters: the no-fly zone in Europe, due to volcanic eruptions in Iceland in April 2010, coincided with travel to Denmark for module two. The cost of travel to, and accommodation in the five countries, 
plus the 9-week absence from the workplace, add to the expense of the programme. Financial viability for the partner organizations and affordability for students are even more critical now that many countries are experiencing an economic recession. There is more competition with the growth in multi-disciplinary masters, professional masters and new masters in occupational therapy offered by a single country with fees paid through a government subsidy or on-line as distance learning. Some of these new master degrees are led by OTEuroMaster alumni, an example of the success of academic capacity building. Each partner also balances the tension between sustaining a strong international programme and enhancing national masters that meet national competency requirements.

It is paradoxical that financial viability is such a threat when "internationalization" has become a key goal of higher education institutions worldwide. A recent report describes collaboration as "absolutely necessary (because) it will foster - if framed by ambitious initiatives - the development of a 'global civil society' which will bind universities and countries together through common values and principles" (UK/US Study Group, 2009, summary). This report notes the impediments to international partnerships - different accreditation requirements, legal restrictions on funding access and disparities in revenue models - all of which continue to affect the OT-EuroMaster. In addition to the lack of government subsidy for international programmes, there is increasing anecdotal evidence of employers' limiting support, both financial and time, for continuing professional development unless it is relevant to the workplace.

The current economic recession jeopardizes the future of international partnerships even though they can contribute to the advancement of occupational therapy and a global civil society. However, there are some opportunities. One is the increasing recognition of joint degrees in Europe that means that students would be eligible for government education grants. This has been an aspiration since the start but has not yet been possible because national law in many European countries does not permit joint degrees. Technological advances offer another opportunity. These could offer the facility for blended e-learning, combining the power of personal contact in different cultural contexts with on-line learning.

The contemporary challenges and opportunities suggest that it would be timely to reappraise the OT-
EuroMaster, to consider new directions such as a training network for doctoral students and transnational research. This would build on the academic capacity building successes whilst retaining the original vision of the OTEuroMaster and may secure the longer term future. Other possibilities include sharing our experiences and curricula design to facilitate similar collaborations in more regions of the world. All these opportunities are under currently under consideration.

\section{Conclusion}

An intrinsic case study identified four factors that have sustained an international, post graduate programme since 1999. The original shared vision of enhancing the academic status of occupational therapy remains pertinent. The programme brought this vision to reality through collaboration to create a critical mass of academic faculty from five countries. By February 2013, graduates have produced 42 peer reviewed publications and six have completed doctoral studies. Faculty with a $\mathrm{PhD}$ has become the norm. However, these are only proxy measures of academic development. Further research, including destination studies, is needed to capture a broader range of outcomes and longitudinal views from practice, education and societal perspectives.

International educational partnerships are demanding and rewarding, especially those offering "internationalization abroad". Time and commitment are required to create and maintain trust between individuals and organizations. However, the benefit is the gestalt, where the whole is much greater than the sum of the parts.

\section{Acknowledgements}

We are indebted to everyone who has contributed to the success of the European Master of Science in Occupational Therapy over the years.

\section{REFERENCES}

Bologna Declaration (1999). Joint declaration of the European Ministers of Education. The European Higher Education Area. (Available at: http://www.ond.vlaanderen. be/hogeronderwijs/bologna/documents/mdc/bologna_ declaration1.pdf) (Accessed 24 February 2013).

Clarke CL, Reed J (2010). Case study research. In: Gerrish K, Lacey A (eds). The Research Process in Nursing. (pp. 237-247). Oxford: Wiley-Blackwell. 
COTEC (2011). Summary of the occupational therapy profession in Europe. Council of Occupational Therapists for the European Countries. (Available at: http://www. cotec-europe.org/userfiles/file/\%20ot\%20summary/ COTEC\%20Summary\%20of\%20the\%20OT\%20profession\%20in\%20Europe\%202011.pdf) (Accessed 19 May 2012).

De Wit H (2010). Internationalization of higher education in Europe and its assessment, trends and issues. NVAO Nederlands-Vlaamse Accreditatieorganisatie. (Available at: http://www.nvao.net/page/downloads/Internationalisation of_Higher_Education_in_Europe_DEF_december_2010.pdf) (Accessed on 2 November 2012).

ENOTHE (2000). Occupational Therapy Education in Europe: an exploration. Chapter 3. (Available at: http:// www.enothe.eu/index.php?page=about/facts_and_figures) (Accessed on 2 November 2012).

Humbert TK, Burket A, Deveney R, Kennedy K (2011). Occupational therapy students' perspectives regarding international cross-cultural experiences. Australian Occupational Therapy Journal. 58(4): 300-309. DOI: $10.1111 /$ j.1440-1630.2011.00987.x

Kinèbanian A, Runge U, Tigchelaar E (2007). The European Master of Science in Occupational Therapy: a vision come true. Journal of Allied Health 36(2): e160-e178.

Kinėbanian A, Stomph M (2009). Guiding principles on diversity and culture. World Federation of Occupational Therapists. (Available at: http://www.wfot.org/Store/tabid/ 61/CategoryID/4/ProductID/30/Default.aspx) (Accessed 5 January 2013).

Knipper M, Seeleman C, Essink-Bot M-L (2010). How should ethnic diversity be represented in medical curricula? A plea for systematic training in cultural competence. Tijdschrift voor Medisch Onderwijs 29(1): 54-60. DOI: 10.1007/s12507-010-0010-8

Momeni P, Jirwe M, Esmani A (2008). Enabling nursing students to become culturally competent - a documentary analysis of curricula in all Swedish nursing programs. Scandinavian Journal of Caring Sciences 22: 499-506. DOI: 10.1111/j.1471-6712.2007.00554.x

NVAO (2009). Advisory Report Accreditation European Master of Science in Occupational Therapy. (Available at: http://search.nvao.net/files/id_225_rapport\%20HvA \%20wo-ma\%20European\%20Master\%20of\%20Science \%20in\%20Occupational\%20Therapy.pdf) (Accessed on 20 May 2012).

NVAO (2010a). The assessment of internationalization. An evaluation of the NVAO's pilot procedures. Report. (Available at: http://nvao.com/page/downloads/ Assessment of Internationalisation - an evaluation of the NVAOs pilot procedures.pdf) (Accessed on 13 October 2012).

NVAO (2010b). Assessment of internationalisation as a distinctive (quality) feature. Panel Report. (Available at: http://search.nvao.net/files/id_225_report $\% 20$ HvA\%20hbo-ma\%20European\%20MSc\%20in\%20 Occupational\%20Therapy\%20BKK.pdf) (Accessed on 20 May 2012).

Roberts AEK, MacRae A, Kinébanian A, Strong J, Stadnyk R (2003). Innovative advanced master's degree programs around the world. WFOT Bulletin 48(November): 41-48.

Seeleman C, Suurmond J, Stronks K (2009). Cultural competence: a conceptual framework for teaching and learning. Medical Education 43(3): 229-237. DOI: 10.1111/j.1365-2923.2008.03269.x

Stake RE (1995). The Art of Case Study Research. Thousand Oaks: Sage.

UK/US Study Group (2009). Higher education and collaboration in a global context. Building a Global Civil Society. UK/US Study Group. A private report to Prime Minister Gordon Brown. (Available at: www.aau.edu/ WorkArea/showcontent.aspx?id=9222) (Accessed 19 May 2012). 